\title{
Utilização de serragem e bagaço de cana-de-açúcar para adsorção de cádmio
}

Use of sawdust and pulp from cane as adsorbents of cadmium

\author{
Silvana ALBERTINI ${ }^{1}$, Leandro Francisco do CARMO $^{1 *}$, Luiz Gonzaga do PRADO FILHO ${ }^{1}$
}

\begin{abstract}
Resumo
Os metais provenientes de atividades antropogênicas contaminam o ambiente, insumos e matérias-primas e, conseqüentemente, a cadeia trófica, alcançando assim o homem. Em função do acúmulo desses metais, bem como de suas conseqüências danosas, estão sendo realizados estudos para avaliar os níveis alcançados por tais contaminações. O objetivo deste trabalho foi testar a capacidade da serragem e do bagaço de cana-de-açúcar, em adsorver metais pesados a partir de soluções modelo de cloreto de cádmio, nas concentrações de 25 e 50 mg. L $^{-1}$. As triplicatas das amostras tomadas para análise foram secas ao ar em ambiente arejado, sem quaisquer processamentos, sendo os experimentos conduzidos com 10 g de resíduo e $500 \mathrm{~mL}$ de solução de cloreto de cádmio em reatores de PVC com capacidade de $1300 \mathrm{~mL}$, e a homogeneização feita manualmente durante o contato de até 16 horas $^{32}$. Como a capacidade de adsorção do metal pela serragem não foi esgotada na primeira utilização, estudou-se a possibilidade de um novo contato reutilizando-se a solução remanescente, mantendo a proporção 1:5032. Numa segunda etapa, foram testados tempos de 12, 8 e 4 horas. O teor de cádmio foi determinado por espectrofotometria de absorção atômica (EAA) na solução de contato, após separação da serragem por filtração. Pelos resultados obtidos, podemos dizer que estes resíduos podem ser utilizados como adsorventes de metais pesados no tratamento de efluentes.
\end{abstract}

Palavras-chave: metal pesado; adsorção; cádmio; resíduo; contaminação.

\begin{abstract}
Metals which come from anthropogenic activities contaminate the atmosphere, inputs and raw materials and, consequently, the trophic chain, thus affecting humankind. Due to the accumulation of these metals, as well as their harmful consequences, studies are being carried out to evaluate the levels reached by such contaminations. The objective of this work was to test the capacity of the sawdust and pulp from cane, in adsorber heavy metals from model solutions of chloride of cadmium, at the concentrations of 25 and 50 mg. $\mathrm{L}^{-1}$. The triplicates of samples taken for analysis were dried in the air in an airy atmosphere, without any processes, and the experiments were done with $10 \mathrm{~g}$ of residue and $500 \mathrm{~mL}$ of solution of chloride of cadmium in PVC reactors with a capacity of $1300 \mathrm{~mL}$, where the homogeinization was made manually during the contact of 16 hours ${ }^{25}$. As the capacity of adsorption of the metal for the residue was not drained at first, the possibility of a new contact reusing the remaining solution was studied, maintaining the proportion at 1:5025. In a second stage they were tested at times of 12, 8 and 4 hours. The amount of cadmium was determined by the atomic absorption spectrofotometry (AAS) in the contact solution, after separating the residue for filtration. According to the results, we can say that these residues can be used as adsorbents of heavy metals in effluent treatment.

Keywords: heavy metal; adsorption; cadmium; residue; contamination.
\end{abstract}

\section{Introdução}

O constante crescimento demográfico e industrial, agregado à ocupação desordenada e ao uso inadequado da água e do solo, resulta sempre em poluição do ambiente ${ }^{2,30}$. Com a intensificação das atividades antropogênicas, aumentou a emissão de metais, que vêm sendo manipulados pelo homem desde os tempos mais remotos ${ }^{20}$. Esta emissão desordenada torna-se uma preocupação, na medida em que esses elementos, mesmo em pequenas quantidades, se acumulam em reservatórios naturais. As conseqüências danosas que os metais pesados podem causar a médio e longo prazo, quando em contato com o ambiente, insumos e matérias-primas, é um campo que tem despertado o interesse dos pesquisadores, a respeito dos efeitos desta contaminação na flora, fauna e na saúde humana ${ }^{31}$.

A freqüência de efeitos prejudiciais provenientes de intoxicações agudas é mínima, mas o acúmulo de pequenas quantidades no ambiente e na cadeia trófica, constitui-se na

Recebido para publicação em 22/3/2006

Aceito para publicação em 24/1/2007 (001701)

${ }^{1}$ Universidade Metodista de Piracicaba,

Faculdade de Ciências da Saúde, Nutrição,

Rua Tenente Florencio Pupo Netto, 300 dos Americanos,

CEP 16400-000, Lins - SP, Brasil,

E-mail:leandrobio@bol.com.br

*A quem a correspondência deve ser enviada faceta mais importante do comportamento de metais pesados. Uma ação preventiva eficaz a médio e longo prazo pode ser alcançada estudando-se métodos, processos e estratégias que reduzam a permeabilidade da interface crítica a resíduos indesejáveis ao ambiente.

O cádmio é encontrado na natureza quase sempre junto com o zinco, em proporções que variam de 1:100 a 1:1000, na maioria dos minérios e solos. É obtido como subproduto da refinação do zinco e de outros minérios, como chumbo-zinco e cobre-chumbo-zinco.

A galvanoplastia é um dos processos industriais que mais utiliza o cádmio como matéria-prima (entre 45 e 60\% da produção anual). Contudo processos como a fabricação de ligas, varetas para soldagens, baterias $\mathrm{Ni}-\mathrm{Cd}$, varetas de reatores, fabricação de tubos para TV, pigmentos, esmaltes e tinturas têxteis, fotografia, litografia e pirotecnia, estabilizador plástico, fabricação de semicondutores, células solares, contadores de cintilação, retificadores e lasers, também têm importante participação na utilização deste metal ${ }^{26,27}$.

O cádmio existente na atmosfera é precipitado e depositado no solo agrícola na relação aproximada de 3 g.ha-1 ano $^{-1}$. Rejeitos não-ferrosos e artigos que contêm cádmio contribuem significativamente para a poluição ambiental. Outras formas de contaminação do solo são 
os resíduos da fabricação de cimento, da queima de combustíveis fósseis e lixo urbano e de sedimentos de esgotos. $\mathrm{Na}$ agricultura, uma fonte direta de contaminação pelo cádmio é a utilização de fertilizantes fosfatados. Sabe-se que a captação de cádmio pelas plantas é maior quanto menor o $\mathrm{pH}$ do solo. Nesse aspecto, as chuvas ácidas representam um fator determinante no aumento da concentração do metal nos produtos agrícolas.

O cádmio pode interagir com grupos carregados negativamente existentes na parede celular (fosforilas, hidroxilas, carboxilas e sulfidrilas) e, desta forma, ser adsorvido. O metal também pode interagir quimicamente com as manoproteínas e, assim, penetrar pela camada de glucanas, alcançando o citossol através das proteínas transportadoras. Este transporte pode ser feito por duas classes de proteínas transportadoras. As carreadoras são as que se ligam a um soluto específico e sofrem mudanças conformacionais de modo a transferir através da membrana o soluto a elas ligado. A outra classe, as proteínas canais, não necessitam ligar-se ao soluto, pois formam poros hidrofílicos que se estendem através da bicamada lipídica e, quando abertos, permitem que solutos específicos passem por eles, atravessando a membrana numa velocidade muito maior do que o transporte mediado pelas proteínas carreadoras. A retenção de cádmio também pode ser por deposição físicoquímica ou por precipitação inorgânica ${ }^{6}$.

Células vivas e mortas são capazes de acumular metais, podendo apresentar diferenças nos mecanismos envolvidos em cada caso $^{14}$.

Estudos realizados utilizando Saccharomyces cerevisiae, demonstraram que as células mortas foram capazes de remover uma concentração maior de cádmio que as células vivas, sendo que a bioadsorção atingiu seu ápice em 4 horas em células vivas e apenas 2 horas em células mortas ${ }^{10}$.

A concentração de cádmio em efluentes industriais é, geralmente, $1 \mu \mathrm{g} . \mathrm{L}^{-1}{ }^{12}$. Em 1988 no Rio Rimao, no Peru, foi detectada a presença de cádmio em níveis aproximados de $100 \mu \mathrm{g} . \mathrm{L}^{-133}$.

O Conselho Nacional do Meio Ambiente - CONAMA (Resolução $n^{\circ} .20,1986$ ) - , estabelece uma classificação para águas, de acordo com a sua utilização ${ }^{9}$ : abastecimento doméstico; irrigação de hortaliças, de pastagens e aqüicultura, em que os níveis de cádmio, se encontram entre 0,001 e 0,01 mg. $\mathrm{L}^{-1}$. Os efluentes de indústrias ou outras atividades somente poderão ser lançados em corpos de água desde que obedeçam ao valor máximo de 0,2 mg Cd.L-1.

Em trabalhos realizados ${ }^{3}$, verificou-se a absorção e adsorção de cádmio por leveduras, as quais se mostraram capazes de capturar até $6,0 \mathrm{mg} \mathrm{Cd.g^{-1 }}$ biomassa seca, quando colocadas

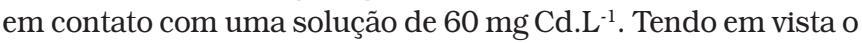
alto valor protéico desta levedura, e também o fato de que sua disponibilidade restringe-se às regiões produtoras de álcool, buscaram-se, no presente, resíduos de grande disponibilidade não apenas nestas regiões alcooleiras.

A madeira vem sendo utilizada pelo homem desde os tempos pré-históricos ${ }^{23,35}$ e a continuidade de seu uso até nossos dias pode ser explicada pela sua beleza e agradabilidade ao tato ${ }^{8}$.
No Brasil, a geração de resíduos florestais tem mostrado valores expressivos, o que nos leva a considerar seriamente a sua utilização na cadeia produtiva. Com uma produção de 22,5 milhões de toneladas de madeira serrada e uma eficiência em torno de $50 \%$, nossa indústria gera nada menos que outros 22,5 milhões de toneladas de resíduos, os quais não representam apenas um problema econômico pelo desperdício, mas também um sério problema ambiental. Os fatores que inibem a plena utilização de resíduos florestais são o custo do transporte, a heterogeneidade, a sazonalidade e a falta de tecnologia e de investimento. A ineficiência deve-se à falta de dimensões entre a oferta e a demanda do produto, a defasagem tecnológica e a mão-de-obra pouco capacitada. Além da falta de eficiência, nossa indústria ainda não sabe o que fazer com seus resíduos. As indústrias madeireiras estão sendo forçadas a resolver o problema de resíduo que não poderá ser simplesmente queimado ou dispensado em locais inadequados. Em várias regiões, onde a exploração da madeira se apresenta como atividade de relevante valor econômico, observa-se um acúmulo significativo destes resíduos ${ }^{29}$. É preciso viabilizar o processamento do resíduo na região em que é gerado e que o absorverá.

Atualmente a grande disponibilidade e o baixo custo dos resíduos agrícolas têm despertado interesses quanto ao seu melhor aproveitamento ${ }^{4}$. Milhões de toneladas de palha de cereais são produzidos no mundo anualmente e, na maioria das vezes, removidas do campo por queimadas provocando problemas de poluição ambiental ${ }^{25}$.

A cana-de-açúcar, originária da Índia, chegou ao Brasil em $1522^{5}$ e, atualmente, é explorada em quase todo o país ${ }^{34}$, que apresenta 5,4 milhões de hectares cultivados ${ }^{11,16}$, sendo considerado o maior produtor mundial e o país com maior potencial de expansão em área plantada ${ }^{24}$. A queima dos canaviais antecedendo a colheita de cana-de-açúcar, que vem sendo adotada pela maioria dos plantadores por facilitar e melhorar o rendimento do corte manual e por diminuir os acidentes de trabalho ${ }^{21}$, é considerada uma atividade tipicamente poluidora, visto que degrada o meio ambiente e traz problemas de saúde pública ${ }^{17}$, pois lança anualmente na atmosfera aproximadamente 64,8 milhões de toneladas de gás carbônico, que contribuem para a diminuição da qualidade do ar e o aumento do efeito estufa ${ }^{22}$.

No Brasil, com a proibição da despalha da cana-de-açúcar, estabelecendo um período de transição de 8 anos até a proibição total, observa-se a colheita mecanizada de cana crua ${ }^{15}$, na qual a palhada proporciona melhor qualidade industrial da cana, maior proteção do solo contra erosão, melhor retenção de umidade do solo, maior atividade microbiana no solo e seu enriquecimento em matéria orgânica, controle de ervas daninhas, suspensão da operação de queima e menor impacto ambiental ${ }^{7,13}$. Estes resíduos que permanecem no solo e ainda não são explorados no Brasil, apresentam quantidades que variam com a idade, variedade e com o local do plantio, que podem oscilar entre 6 t.ha $^{-1}$ e 22,8 t.ha $^{-1}$ de palhada ${ }^{28}$. A quantidade de resíduos pode chegar a $1 / 5$ do peso total da cana e, desta forma, causar problemas para as operações de pós-colheita ${ }^{18}$. Estima-se que, além da quantidade de bagaço 
processado e utilizado para alimentar caldeiras, haja um excedente de bagaço de cana-de-açúcar correspondente a $8 \%$ nas destilarias anexas e $12 \%$ nas autônomas, que poderia ter outros destinos, inclusive ser empregado de forma a melhorar a qualidade do meio ambiente ${ }^{1}$.

O presente trabalho tem como objetivo estudar o uso de serragem e de bagaço de cana-de-açúcar como materiais adsorventes de metais pesados, considerando-se uma fonte conhecida de emissão e constituindo estes resíduos, barreira contra a disseminação do metal para o ambiente.

\section{Material e métodos}

O material utilizado nos experimentos foi colocado em contato com solução de lavagem por 4 horas $^{19}$, enxaguado com água deionizada e seco. As concentrações de sal de cádmio utilizadas em ensaios de biossorção estão entre 10 a 200 mg Cd.L ${ }^{-1}{ }^{32}$ Para este trabalho, foram utilizadas soluções de cloreto de cádmio $\left(\mathrm{CdCl}_{2} 21 / 2 \mathrm{H}_{2} \mathrm{O}\right)$ nas concentrações de 25 e $50 \mathrm{mg}$. $\mathrm{L}^{-1}$, que simulam eventuais efluentes líquidos. A serragem utilizada neste experimento é constituída de eucalipto, cedro, pinho e madeiras duras, porém sem proporções conhecidas. O bagaço de cana-de-açúcar utilizado está na forma "in natura". Os dois resíduos foram secos em ambiente arejado, sem quaisquer processamentos, visando mínimos custos de processamento referentes a gastos com energia e tempo.

Os experimentos foram conduzidos em reatores constituídos de tubo de PVC de 7,5 cm de diâmetro e $30 \mathrm{~cm}$ de altura, com capacidade volumétrica de $1300 \mathrm{~mL}$, fechado apenas na base. O equipamento era provido de um homogeneizador manual de movimentos verticais, constituído de chapa de PVC, com 6,0 cm de diâmetro, recortes nas bordas e haste central de bastonete de PVC de $40 \mathrm{~cm}$, cuja função era evitar a formação de gradiente de concentração na solução, durante os tempos de contato. Para minimizar eventual evaporação da solução, a extremidade superior do reator foi vedada com tampa de folha de alumínio com orifício central para a passagem da haste do homogeneizador, o qual permaneceu dentro do reator durante todo o tempo de contato, não sendo necessário descobri-lo para proceder à homogeneização. As análises foram conduzidas em triplicatas, mantidas numa faixa de temperatura de 21-23 ${ }^{\circ} \mathrm{C}$.

Para o primeiro período de contato, os experimentos foram realizados com 10 g de resíduo e $500 \mathrm{~mL}$ de solução de cloreto de cádmio de concentração conhecida, mantendo-se a proporção 1:50 e um tempo de contato de 16 horas $^{32}$. Em seguida, os resíduos foram descartados e as respectivas soluções de contato filtradas foram reservadas. Para o segundo período de contato, foram tomadas alíquotas de $250 \mathrm{~mL}$ de cada solução de contato remanescentes, as quais foram acrescidas de $5 \mathrm{~g}$ dos respectivos resíduos novos, bagaço de cana-de-açúcar e serragem. Para o terceiro contato, reutilizando a solução filtrada do experimento anterior, os experimentos foram realizados com 2,5 g de resíduo e $125 \mathrm{~mL}$ de solução de contato, mantendo a concentração de 1:50 entre o resíduo e solução de contato.

Após os respectivos tempos de contato, o resíduo foi separado por filtração ${ }^{32}$ e, o teor de cádmio foi determinado por espectrofotometria de absorção atômica (EAA), em espectrofotômetro Varian, modelo AA-175, seguindo os parâmetros do manual do fabricante, que acompanha o aparelho, sem ajustes especiais.

A concentração do metal adsorvido pelo resíduo foi calculada pela diferença de concentração entre as soluções inicial e final, expressa em mg. $\mathrm{kg}^{-1}$ de resíduo. Posteriormente, foram estudados tempos de contato menores, de 12, 8 e 4 horas.

As análises estatísticas foram realizadas através do programa SAS.

\section{Resultados e discussão}

Pelos resultados obtidos com o experimento que empre-

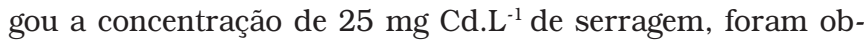
servadas diferenças significativas $(P<0,05)$ entre os quatro tempos empregados (Tabela 1). Os tempos de 8, 12 e 16 horas apresentaram diferenças significativas $(P<0,05)$ e foram considerados eficientes quanto ao processo de adsorção do metal presente na solução inicial. Nos dois tratamentos de reutilização subseqüentes, a baixa concentração adsorvida, foi provavelmente em função da baixa concentração do metal presente nas respectivas soluções remanescentes, uma vez que a probabilidade de contato entre o metal e a serragem foi menor (Figura 1).

A baixa concentração de metal adsorvido pela serragem no tempo de 4 horas permite afirmar que este tempo de contato foi insuficiente para que o metal presente na solução inicial fosse adsorvido pela serragem, apontando para uma não diluição da solução por entre as partículas dos resíduos. Os quatro tratamentos no tempo de 8 horas consecutivas com o mesmo resíduo apresentaram uma adsorção maior que aqueles em que houve substituição dos resíduos a cada quatro horas (Figura 1 e 2).

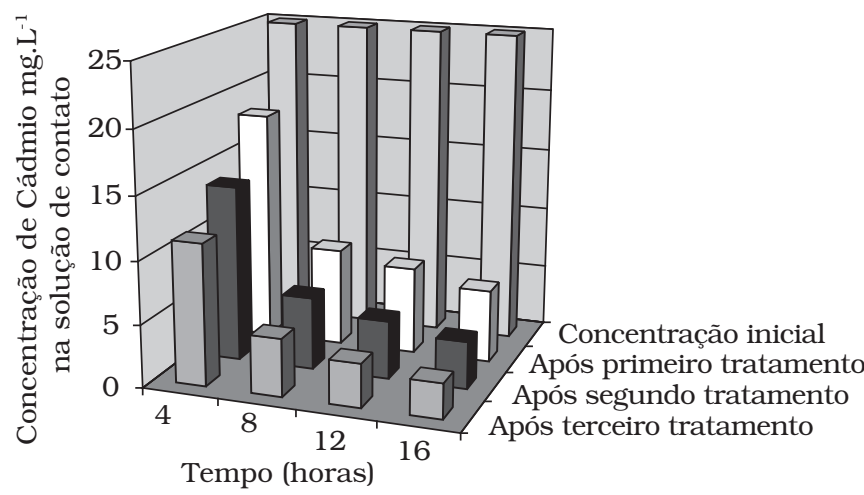

Figura 1. Adsorção de cádmio por serragem em solução de contato

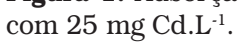

Igualmente ao observado no experimento que empregou

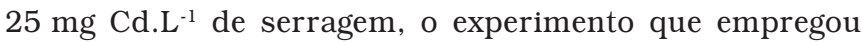
$50 \mathrm{mg} \mathrm{Cd} . \mathrm{L}^{-1}$ com serragem também apresentou diferenças significativas $(\mathrm{P}<0,05)$ entre os quatro tempos empregados (Figura 2). Os tempos de 8, 12 e 16 horas também apresentaram diferenças significativas $(\mathrm{P}<0,05)$ e foram considerados 
mais eficientes quanto ao processo de adsorção do metal presente na solução inicial, uma vez que no tempo de 4 horas, a diferença entre os contatos foi maior. Da mesma forma que

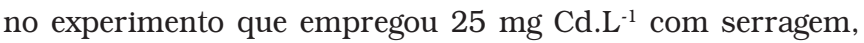
no experimento que empregou $50 \mathrm{mg} \mathrm{Cd} . \mathrm{L}^{-1}$ com serragem, foi observado uma baixa adsorção do metal nos dois tratamentos de reutilização subseqüentes, o que também pode ser justificado pela baixa concentração do metal presente nas respectivas soluções remanescentes, visto que a probabilidade do contato entre o metal e a serragem é menor.

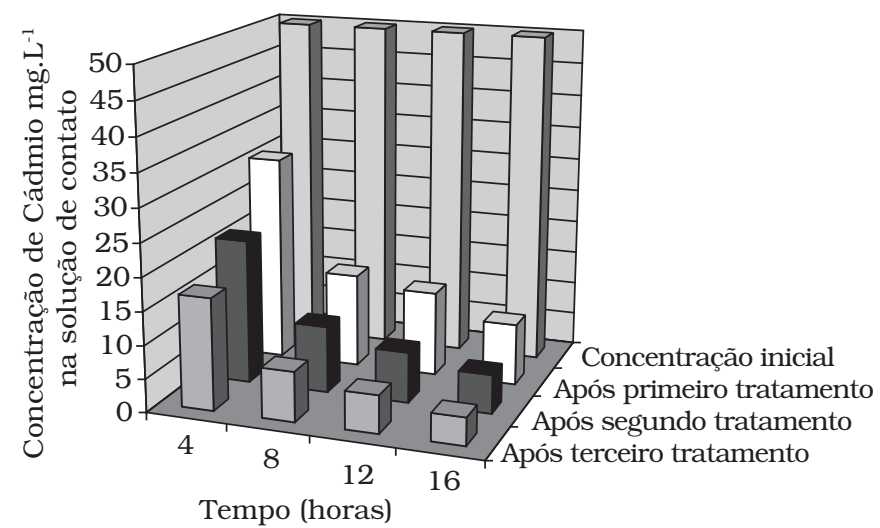

Figura 2. Adsorção de cádmio por serragem em solução de contato

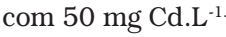

No experimento que empregou a concentração de

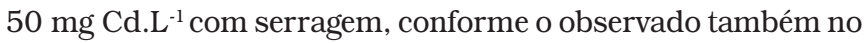

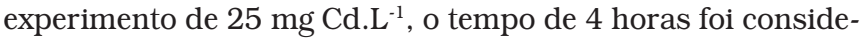
rado insuficiente para que o metal presente na solução inicial fosse satisfatoriamente adsorvido pela serragem, e a elevada concentração do metal presente nas soluções remanescentes pode justificar uma elevada adsorção do metal nos dois tratamentos de reutilização.

Aqui, como no experimento anterior de concentração $25 \mathrm{mg} \mathrm{Cd}$. $\mathrm{L}^{-1}$ de serragem, nota-se que mesmo seqüenciais, os tratamentos de 4 horas, com a troca do resíduo, os quais perfazem um total de tratamento de 12 horas, a absorção é menor que no tratamento de 12 horas consecutivas, sem a troca do resíduo, o que novamente indica a existência de um tempo para que se processe a adsorção, provavelmente pela não difusão da solução de contato pelo resíduo (Figuras 1 e 2).

No experimento que empregou a concentração de

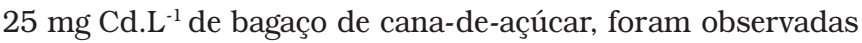
diferenças significativas $(\mathrm{P}<0,05)$ entre os quatro tempos empregados. O tempo de $12 \mathrm{~h}$ apresentou uma adsorção significantemente maior $(\mathrm{P}<0,05)$ que os tempos de $16,8 \mathrm{e}$ 4 horas em ordem respectivamente decrescente.

A baixa concentração de metal adsorvido pela serragem no tempo de 4 horas permite afirmar que este tempo de contato foi insuficiente para que o metal presente na solução inicial fosse adsorvido pela serragem, apontando para uma não diluição da solução por entre as partículas dos resíduos. Os tratamentos no tempo de 8 horas consecutivas com o mesmo resíduo apresentam uma adsorção maior que aqueles em que há uma substituição dos resíduos por resíduos novos a cada quatro horas (Figura 3).

Desta forma, esta maior concentração do metal presente nas soluções remanescentes pode justificar o fato dos dois tratamentos de reutilização subseqüentes apresentarem uma elevada adsorção do metal pelo bagaço de cana-de-açúcar,

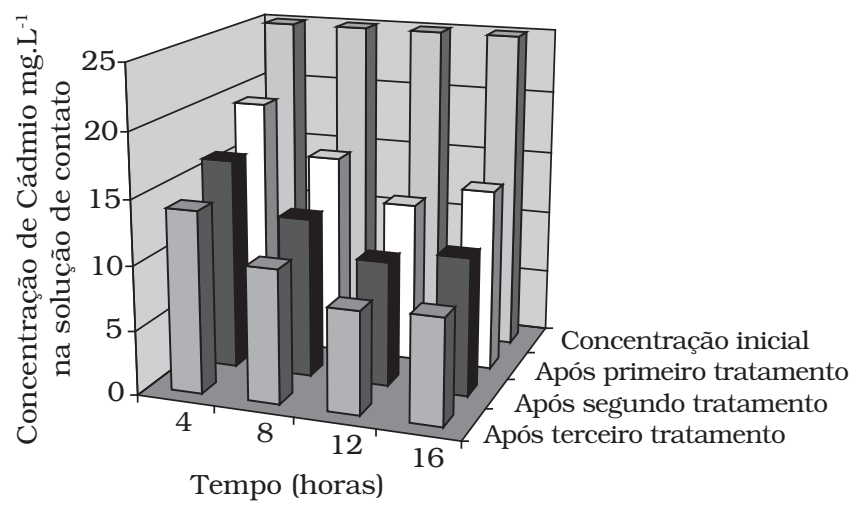

Figura 3. Adsorção de cádmio por bagaço de cana-de-açúcar em solução de contato com $25 \mathrm{mg} \mathrm{Cd} \cdot \mathrm{L}^{-1}$.

quando comparados aos tratamentos em tempos maiores (8, 12 e 16 horas).

No experimento que empregou a solução com $25 \mathrm{mg} \mathrm{Cd.L^{-1 }}$ em contato com o bagaço de cana-de-açúcar, foram observadas diferenças significativas. Tanto no tratamento inicial como na primeira reutilização, com um tempo de 16 horas, foi observado um aumento da concentração de cádmio na solução de contato, o que sugere que este metal esteja voltando para a solução após contato em períodos superiores a 12 horas. Tal fato pode ser explicado pela diluição de açúcares, compostos fenólicos e outras substâncias polares que, nesses tempos de contato, saem do resíduo, levando consigo o metal, que retorna para a solução.

No experimento que empregou a concentração de $50 \mathrm{mg} \mathrm{Cd} . \mathrm{L}^{-1}$ de bagaço de cana-de-açúcar, foram observadas diferenças significativas $(P<0,05)$ entre os quatro tempos empregados. O tempo de $16 \mathrm{~h}$ apresentou adsorção significantemente superior $(\mathrm{P}<0,05)$ aos tempos de 12,8 e 4 horas em ordem respectivamente decrescente (Figura 4).

O tempo de 4 horas, igualmente ao que foi observado no

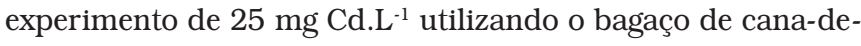
açúcar, foi insuficiente para que o metal fosse adsorvido, e a concentração do metal presente nas soluções remanescentes foi responsável pela elevada adsorção do metal pelo bagaço de cana-de-açúcar nos dois tratamentos de reutilização subseqüentes, quando comparados aos tempos maiores $(8,12 \mathrm{e}$ 16 horas).

Para as duas concentrações empregadas nos experimentos (25 e $50 \mathrm{mg} \mathrm{Cd} . \mathrm{L}^{-1}$ ), observou-se que os dois resíduos empre- 


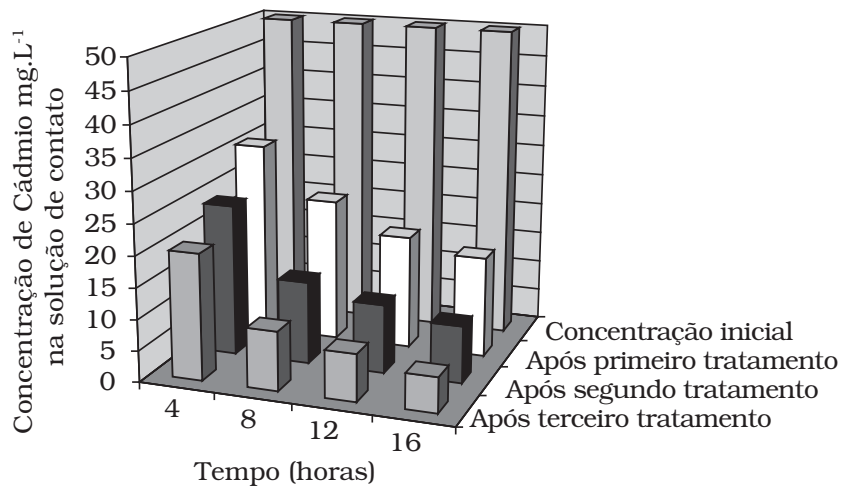

Figura 4. Adsorção de cádmio por bagaço de cana-de-açúcar em solução de contato com $50 \mathrm{mg}$ Cd.L $\mathrm{L}^{-1}$.

gados como materiais adsorventes de metais pesados apresentaram semelhanças quanto ao processo de adsorção no tempo de 4 horas (Tabela 1). A adsorção do metal pelos dois resíduos não foi satisfatória nos tratamentos correspondentes ao tempo de 4 horas, o qual pode ser eleito como insuficiente para um perfeito contato entre o metal e os materiais absorventes. Nos tempos de 8, 12 e 16 horas a serragem apresentou uma adsorção significantemente superior $(\mathrm{P}<0,05)$ ao do bagaço de cana-de-açúcar.

Tabela 1. Concentração média de cádmio adsorvida pela serragem e pelo bagaço de cana-de-açúcar (mg Cd.L $\mathrm{L}^{-1}$ ) empregando duas concentrações e um tratamento inicial.

\begin{tabular}{rrrrrc}
\hline \multirow{2}{*}{$\begin{array}{c}\text { Tempo } \\
\text { (h) }\end{array}$} & \multicolumn{4}{c}{ Tratamento inicial } \\
\cline { 2 - 3 } \cline { 5 - 6 } \cline { 5 - 6 } & \multicolumn{2}{c}{$25 \mathrm{mg} \mathrm{Cd.L^{-1 }}$} & & \multicolumn{2}{c}{$50 \mathrm{mg} \mathrm{Cd.L^{-1 }}$} \\
\cline { 2 - 3 } & Serragem & $\begin{array}{c}\text { Bagaço de } \\
\text { cana-de-açúcar }\end{array}$ & & Serragem & $\begin{array}{c}\text { Bagaço de } \\
\text { cana-de-açúcar }\end{array}$ \\
\hline 4 & $6,5850^{\text {d }}$ & $5,4630^{\mathrm{d}}$ & & $18,8604^{\mathrm{d}}$ & $18,8970^{\mathrm{d}}$ \\
8 & $17,1805^{\mathrm{c}}$ & $9,3147^{\mathrm{c}}$ & & $35,8368^{\mathrm{c}}$ & $27,2014^{\mathrm{c}}$ \\
12 & $18,0436^{\mathrm{b}}$ & $12,5330^{\mathrm{a}}$ & & $37,2400^{\mathrm{b}}$ & $31,7470^{\mathrm{b}}$ \\
16 & $19,1830^{\mathrm{a}}$ & $10,8800^{\mathrm{b}}$ & & $40,6901^{\mathrm{a}}$ & $33,8433^{\mathrm{a}}$ \\
\hline
\end{tabular}

O fato de a porcentagem de Cd adsorvido ser maior quando se coloca o resíduo em contato com uma solução de concentração 50 mg. $\mathrm{L}^{-1}$, em comparação com uma solução de $25 \mathrm{mg} . \mathrm{L}^{-1}$, pode ser explicado pela relação entre a concentração do reagente $\left(\mathrm{Cd}^{+2}\right)$ e os sítios de fixação, onde a adsorção tende a ser maior quando se tem um equilíbrio entre as concentrações de íons $\mathrm{Cd}^{+2}$ e os sítios de fixação, ou seja, na solução de concentração de $50 \mathrm{mg}$. $\mathrm{L}^{-1}$, a quantidade de íons $\mathrm{Cd}^{+2}$ passíveis de fixação é o dobro da quantidade encontrada na solução de 25 mg. L $^{-1}$, para uma mesma quantidade de sítios disponíveis para o processo de adsorção.

Embora os dois resíduos sejam passíveis de serem utilizados como materiais absorventes, o uso destes pós-adsorção, se mostra como uma nova problemática, sendo necessários novos estudos para definir seu destino.

\section{Conclusão}

Para os dois resíduos empregados (serragem e bagaço de cana-de-açúcar) o tempo de 4 horas se mostrou insuficiente para promover a adsorção.

Pelos resultados obtidos nos tempos de contato de 8, 12, e 16 horas, pode-se inferir que a serragem e o bagaço de canade-açúcar são resíduos agroindustriais passíveis de serem utilizados como materiais absorventes de metais pesados no tratamento de efluentes.

\section{Referências bibliográficas}

1. AGUIAR, C. L.; MENEZES, T. J. B. Conversão enzimática do bagaço de cana-de-açúcar. Biotecnologia Ciência \& Desenvolvimento, Brasília, v. 5, n. 26, p. 52-55, maio/junho 2002.

2. ALABURDA, J. Surfactantes em águas de abastecimento público. Boletim do Instituto Adolfo Lutz, São Paulo, v. 9, n. 1, p. 12-13, 1999.

3. ALBERTINI. S.; CARMO, L. F.; PRADO-FILHO, L. G. Isotermas de Adsorção de Cádmio por Saccharomyces cerevisiae. Ciência e Tecnologia de Alimentos, Campinas, v. 2, n. 21, p. 134-38, 2001.

4. ANTUNES, L. A. F.; CEREDO, M. P.; CAMARGO, K. Decomposição simulada da palha de arroz e obtenção de microrganismos celulolíticos. Arquivos de Biologia e Tecnologia Curitiba, Curitiba, v. 29, n. 3, jul. 1986.

5. BASTOS, E. Cana-de-açúcar: o verde mar de energia. São Paulo: Ícone, 1987. 130p.

6. BRACTHET, J.; MIRSKY, A. The cell: biochemistry, physiology, morphology; New York: Academic Press, v. 6. 1964. 564 p.

7. CALDEIRA, D. S. A. Palhada residual de cana-de-açúcar (Saccharum spp.) colhida mecanicamente (sem queima prévia): manejo, fertilização, influência no perfilhamento e produtividade da cultura. Botucatu, 2002, 94 p. Tese (Doutorado). Faculdade de Ciências Agronômicas, Universidade Estadual Paulista "Júlio de Mesquita Filho", Botucatu, 2002.

8. CARPINELLI, S. M. Rendimento no desdobro e produtividade em madeira serrada de uma floresta de Eucalyptus grandis. Piracicaba, 2002, 76 p. Dissertação (Mestrado). Escola Superior de Agricultura "Luiz de Queiroz", Piracicaba, 2002.

9. CONSELHO NACIONAL DO MEIO AMBIENTE. Lei ${ }^{\circ} 20$ de 31 de junho de 1986. Disponível em: http://www.mma.gov.br/port/ conama/res/res86res2086.htm Acesso em: 16 nov. 2006.

10. DEL RIO, D. T. Biossorção de cádmio por leveduras Saccharomyces cerevisia. 2004. 54 p. Dissertação (Mestrado) - Escola Superior de Agricultura "Luiz de Queiroz", Universidade de São Paulo, Piracicaba, 2004.

11. FALÓTICO, M. H. B. Distribuição das concentraçóes de metais em água, matéria em suspensão e sedimento de fundo na bacia do Rio Piracicaba, SP. Piracicaba, 2001. 92p. Tese (Doutorado) - Escola Superior de Agricultura “Luiz de Queiroz", Universidade de São Paulo, Piracicaba, 2001.

12. FRIBERG, L.; NORDBERG, G.F. VOUK, V.B. Handbook of the toxicology of metals. 2. ed. Amsterdam: Elsevier, 1986. $2 \mathrm{v}$.

13. FURLANI NETO, V. L. Colheita mecanizada da cana-de-açúcar. STAB. Açúcar Álcool e Subprodutos, Piracicaba, v. 12, n. 3, p. 8-9, jan./fev. 1994.

14. GAAD, G. M.; WHITE, C. Microbial treatment of metal pollution - working biotechnology? Tibtechnology, Oxford, v. 11, n. 8, p. 353-359, 1993. 
15. GONÇALVES, J. S.; SOUZA, S. A. M. Proibição da queima de cana no Estado de São Paulo: simulações dos efeitos na área cultivada e na demanda pela força de trabalho. Informações Econômicas, São Paulo, v. 28, n. 3, p. 21-40, 1998a.

16. GONÇALVES, J. S.; VEIGA FILHO, A. A. Açúcar e álcool. Prognóstico Agrícola, São Paulo, v. 2, n. 2, p. 141-150, 1998b.

17. GOULART, M. P. Legislação ambiental e queimada de cana. In: SEMANA DA CANA-DE-AÇÚCAR DE PIRACICABA, 2., Piracicaba. Resumos... Piracicaba: FEALQ, 1997. p. 61-66.

18. LOPES, O. O palhiço. Brasil Açucareiro, Rio de Janeiro, v. 75, p. 64-67, 1970.

19. MARTIN, T. D.; STEPHEN, E. Sample preparation procedure for spectrochimical determination of total recoverable elements. In: MARTIN, T. D.; CREED, J. T.; LONG, S. E. Methods for the determination of metals in environmental samples. Boca Raton: SMOLEY, 1992. Chap. 2, p. 15-24.

20. MURATA, I.T.F; PASCUET, N.S.; NUNES, M.C.D. Importância do controle de metais pesados em alimentos. Boletim do Instituto Adolfo Lutz, São Paulo, v. 9, n. 1, p. 10-12, 1999.

21. Oliveira, M. W.; TRIVElin, P. C. O.; GAVA, G. J. de C.; PENATTI,C.P. Degradação da Palhada de cana-de-açúcar. Scientia Agrícola, Piracicaba, v. 56, n. 4, p. 803-809, 1999.

22. OS IMPACTOS da queima da cana. BIO. Revista Brasileira de Saneamento e Meio Ambiente, São Paulo, v. 10, p. 42-48, 1999.

23. PERLIN, J. História das florestas: a importância da madeira no desenvolvimento da civilização. Rio de Janeiro: Imago, 1992. $490 \mathrm{p}$.

24. REIS JÚNIOR, R. dos A. Diagnose nutricional da canade-açúcar com o uso do sistema integrado de diagnose e recomendação (DRIS). Rio de Janeiro, 1999, 141 p. Dissertação (Mestrado) - Universidade Estadual do Norte Fluminense, Rio de Janeiro, 1999.

25. ROBERTO, I. C.; SILVA, S. S.; FELIPE, M. G. A.; MANCILHA, I. M.; SATO, S. Bioconversion of rice straw hemicellulose hydrolysate for the production of xylitol - effect of ph and nitrogen source.
Applied Biochemistry and Biotechnology, Clifton, v. 57-58, p. 339-47, 1996.

26. SAlGADO, P. E. T. Toxicologia dos metais. In: OGA, S. Fundamentos de toxicologia. São Paulo, 1996. cap. 3.2, p. 154-172.

$27 . \quad$ Metais em alimentos. In: OGA, S. Fundamentos de toxicologia. São Paulo, 1996. cap. 5.2, p. 443-460.

28. SARTORI, M. M. P. Otimização da produção de energia e biomassa do resíduo de colheita em variedades de cana-deaçúcar. Botucatu, 2001. Tese (Doutorado) - Faculdade de Ciências Agronômicas, Universidade Estadual Paulista "Júlio de Mesquita Filho", Botucatu, 2001. 108 p.

29. SOUZA, M. R. de Tecnologias para usos alternativos de resíduos florestais: experiência do laboratório de produtos florestais - IBAMA na área de utilização de resíduos florestais e agrícolas. In: WORKSHOP SUL-AMERICANO SOBRE USOS ALTERNATIVOS DE RESÍDUOS DE ORIGEM FLORESTAL E URBANA, Curitiba, 1997. Anais... Curitiba: EMBRAPA, 1997. 182 p.

30. STRINGHETA, A. C. O.; CARDOSO, A. A.; LOPES, L. C.; FONTES, L. E. F. Crescimento de crisântemo em substrato contendo composto de lixo urbano e casca de arroz carbonizada II. Revista Ceres, Piracicaba, v. 46, n. 1, p. 175-188, 1999.

31. VERNET, J. P. Heavy metals in the environment. Amsterdam: Elsevier, 1991. chap. 4, p. 95-124. (Trace Metals in the Enviroment, 1).

32. VOLESKY, B. In: Biosorption of heavy metals. Boca Raton: CRC Press, 1990. chap.1.1, p. 3-6: Biosorption and biosorbents.

33. WORLD HEALTH ORGANIZATION. Environmental health criteria n. 134: Cadmium. Disponível: www.inchem.org/documents/jefca/ jecmono/v024je01htm Acesso em: 08 jan. 2004.

34. ZAMBELLO JÚNIOR, E.; AZEREDO, D.F. Adubação na região centro-sul. In: ORLANDO FILHO, J. (Coord.). Nutrição e adubação da cana-de-açúcar no Brasil. Piracicaba: PLANALSUCAR,, 1983. cap. 12 , p.289-313.

35. ZENID, G. J. (Coord.). Madeiras para móveis e construção civil. São Paulo: IPT, [200_].1 CD-ROM. (Publicação IPT, n.2779). 